\title{
O fim de uma company town: do processo de estatização às manifestações dos trabalhadores da Southern Brazil Lumber and Colonization Company (1940-1956) ${ }^{1}$
}

\section{The end of a company town: from the nationalization process to the workers manifestations - the Southern Brazil Lumber and Colonization Company (1940-1956)}

\author{
Soeli Regina Lima* \\ Alexandre Assis Tomporoski**
}

\begin{abstract}
Resumo
O presente trabalho analisa o processo de estatização da Southern Brasil Lumber and Colonization Company, conhecida popularmente como serraria Lumber e da consequente manifestação dos trabalhadores. Sendo a maior serraria da América do Sul no início do século XX, ela implantou uma company town no município de Três Barras-SC. No ano de 1940 a serraria foi estatizada. Nesta fase, a administração estava subordinada a Superintendência das Empresas Incorporadas a União que investiu tanto na produção como na infraestrutura do patrimônio edificado. No ano de 1952 ocorreu a transferência do patrimônio da serraria Lumber para o Ministério do Exército. Foram anos de indecisão quanto ao futuro dos trabalhadores e de atraso nos pagamentos. As manifestações por direitos trabalhistas aconteceram via correspondências e encontros com representantes do governo. Para realização da pesquisa foram consultadas as seguintes fontes: imprensa escrita, documentos de ordem legal, correspondências da Superintendência das Empresas Incorporadas a União, entrevistas semiestruturadas e referencial bibliográfico. Concluiuse que contribuíram para a solução da crise trabalhista a organização dos trabalhadores, somada aos interesses da representação política e a participação da imprensa. Muitos trabalhadores migraram para outras cidades e a economia local entrou em declínio. Quando da decisão final sobre a situação trabalhista, em 1956, dos 809 trabalhadores que contava a serraria Lumber
\end{abstract}

\footnotetext{
${ }^{1}$ Pesquisa financiada pela FAPESC.

*Mestre em Geografia pela UFPR. Professora da Universidade do Contestado (UnC).E-mail: soelihistoria@ gmail.com

${ }^{*}$ Doutor em História pela UFSC. Professor do Programa de Mestrado em Desenvolvimento Regional e de diversos cursos de graduação da Universidade do Contestado (UnC), campus Canoinhas. E-mail: alexandre@ unc.br
} 
em 1943, restaram apenas 37 que optaram por permanecer em suas funções, no Ministério da Guerra e 136 que "espontaneamente" resolveram demitir-se.

Palavras-chave: empresas estatizadas; serraria Lumber; trabalhadores.

\begin{abstract}
The present work analyses the nationalization process of the Southern Brazil Lumber and Colonization Company, popularly known as Lumber Sawmill and the consequent workers manifestations. Being the biggest sawmill of South America, in the beginning of the $20^{\text {th }}$ Century, it implanted a company town in the city of Três Barras-SC. In 1940 the Sawmill was nationalized. In that phase the administration was subordinated to the Superintendence of Union Incorporated Enterprises which invested in the production as well as in the infrastructure of built patrimony. In 1952 the company was transferred to the Army Ministry. There were years of indecision concerning the future of workers and delays in payment. The manifestations for working rights happened via mail and meetings with government representatives. For this research the following sources were consulted: written press, documents of legal order, correspondence from the Superintendence of Union Incorporated Enterprises, semi-structured interviews and bibliographic referential. It was concluded that the workers organization added to the political representation interests and the press participation contributed for the solution of the working crisis. Many workers migrated to other cities and the local economy started to decline. When the final decision about the working situation came out, in 1956, from the 809 workers in the sawmill in 1943, only 37 remained, who opted to stay in their functions in the War Ministry, and 136 who "spontaneously" decided to resign.
\end{abstract}

Key-words: nationalized enterprises; Lumber Sawmill; workers.

\title{
Introdução
}

A instalação da Southern Brasil Lumber and Colonization Company,conhecida popularmente como serraria Lumber, pelo Decreto no. 7.426 de 27 de maio de 1909, no planalto Norte catarinense está voltada à construção da estrada de ferro São Paulo- Rio Grande. A concessão do empreendimento teve como parte do pagamento o direito de exploração madeireira. Representando o avanço da ordem capitalista sobre a região, a Lumber além de explorar as terras recebidas na concessão adquire outras; "apenas a família Pacheco vendeu mais de 16 
mil hectares de terras à Lumber em Três Barras". ${ }^{2}$ Desta forma ela "chegou a somar ali 180 mil hectares, responsáveis pela constituição, em Três Barras, da então maior serraria da América do Sul". ${ }^{3}$ Para dar condições de operação e infraestrutura ao empreendimento foi implantada uma company towy, ${ }_{4}^{4}$ pratica recorrente dos grandes industriais da época. Cabe ressaltar que a Lumber atuou também em e em Jaguariaíva e Sengés, no Paraná ${ }^{5}$ e em Calmon ${ }^{6}$, na produção de dormentes, atendendo assim a construção da linha férrea, de madeiras serradas para as estações, alojamento, depósitos e armazéns da companhia.

No ano de 1940, com a política de estatização do governo de Getulio Vargas, a serraria passou a ser administrada pela Superintendência das Empresas Incorporadas da União. Nos primeiros anos da administração a produção foi diversificada, com investimentos no patrimônio edificado. Em 1947 os bens da serraria foram colocados à venda e em 1952 a serraria foi transferida para o Ministério do Exército. A agrura dos trabalhadores inicia com atraso de pagamentos e incerteza de permanência no emprego.

Nesta fase o cenário econômico regional entra em crise. As representações políticas, dos trabalhadores, somadas à participação da imprensa buscam uma solução para a causa trabalhista. Somente em 1957 há um desfecho para os poucos trabalhadores que restaram e aquela que foi outrora uma grande company town transforma-se na sede do CIMH-Campo de Instrução Marechal Hermes, pertencente a 5a Região Militar que implantou um campo de manobras militares na região.

\subsection{Da company town da serraria Lumber: ao processo de estatização.}

No início do século XX, quando da implantação de um empreendimento de grande porte, um dos problemas enfrentados pelos investidores era o

\footnotetext{
${ }^{2}$ MACHADO, Paulo Pinheiro Machado. Lideranças do Contestado: a formação e a atuação das chefias caboclas (1912-1916). Campinas-SP: UNICAMP, 2004. p.143.

${ }^{3}$ AURAS, Marli. Guerra do Contestado: a organização da irmandade cabocla. 2 ed. Florianópolis: Editora da UFSC, 1995.p.100.

${ }^{4}$ Sobre company town da Lumber ver: LIMA, Soeli Regina. Capital transnacional na indústria da madeira em Três Barras: as company towns e a produção do espaço urbano. Dissertação de Mestrado. UFPR, 2007.

${ }^{5}$ Sobre isso ver CARVALHO, Miguel M. X. de. Uma grande empresa em meio à floresta: a história da devastação da floresta com araucária e a Southern Brazil Lumber and Colonization (1870-1970). Tese (Doutorado em História). UFSC, Florianópolis, 2010.

${ }^{6}$ Assim como Três Barras, Calmon pertencia ao Paraná, posteriormente com o Acordo de Limites, pós Guerra do Contestado (1916), passou a jurisdição catarinense. No ano anterior, 1908, "o engenheiro norte-americano Achilles Stengel, nomeado superintendente dos trabalhos da construção da Estrada de ferro São Paulo - Rio Grande montou acampamento em Calmon, em plena zona contestada, e ali pôs em funcionamento o escritório central da obra" (QUEIROZ, 1981, p.69).
} 
de atrair mão de obra para áreas até então sem infraestrutura. A estratégia adotada era a implantação de company town (cidade-empresa).

Três Barras foi inserida neste contexto com a implantação da company town da Lumber. Esta foi criada nas proximidades da estação ferroviária, com infraestrutura necessária, que vieram dar base para a atual configuração espacial urbana do município. Foram projetados tanto os espaços internos da serraria, como: casa das máquinas, almoxarifado, campo de futebol ${ }^{7}$, escritório ${ }^{8}$, armazém, cinema, hospital ${ }^{9}$, casas residenciais; como os externos: cemitério, campo de aviação, traçado de ruas e quadras de Três Barras. Algumas das residências ${ }^{10}$ dispunham de água encanada, energia elétrica, aquecimento central e água quente, provenientes das caldeiras, que moviam a serraria.

Através da Brazil Development and Colonization Company, que fazia parte do holding Brazil Railway Company, a Lumber promoveu a vinda de imigrantes, basicamente da Europa, destacando-se da Polônia e Ucrânia. Eles foram instalados na Colônia Tigre, onde recebiam lotes com posterior pagamento em prestações à empresa. Desta forma a Colônia Tigre serviu de "celeiro" para a Lumber, com o abastecimento de produtos alimentícios para os funcionários da serraria. Merece destaque a família Szczerbowski, ${ }^{11}$ responsável pela fábrica de cigarros, com as marcas Três Barras e Rio Tigre.Todo este projeto conduziu a alterações nas atividades econômicas e sociais. Ela possuía dois "vapores", o "Três Barras" e o "Porto Velho", de médio porte, que auxiliavam no transporte de erva-mate e madeira. ${ }^{12}$ Além de explorar os ervais nativos, das terras recebidas, na concessão ou posteriormente adquiridas, a Lumber também comprava a erva mate, de atravessadores locais, e, através de seus próprios ramais ferroviários, obtinha baixos custos de transporte, proporcionando-lhe vantagem sobre os empresários locais. Havia na cidade: fábrica de caixas, de

\footnotetext{
${ }^{7}$ Foi um dos primeiros campos de futebol com sistema de drenagem da região sul do Brasil. 0 mesmo foi denominado "Estádio Artur Ferreira Ribas", inaugurado em 1918.

${ }^{8}$ Atualmente o espaço serve de escritório da sede do CIMH- Campo de Instrução Marechal Hermes.

${ }^{9}$ Além do hospital, existia a farmácia, que oferecia medicamentos com desconto em folhas de pagamentos. No Museu Municipal de Três Barras é possível analisar, em livros da época, consultas, doenças e medicamentos receitados aos trabalhadores.

${ }^{10}$ Algumas dessas residências assumiram funções diferenciadas como escritórios, refeitórios e residências dos militares no Campo de Instrução Marechal Hermes (CIMH), ali instalado, após a transferência do patrimônio da Lumber para o Ministério do Exército.

${ }^{11}$ LIMA, Soeli Regina; TONON, Eloy; NAHIRNE, Kelen. O acervo fotográfico de Luis Szczerbowski:fragmentos da memória.IN: REVISTA Memória em Rede. Pelotas, v.8, n.14, Jan./Jun.2016. p. 169- 175.

${ }^{12}$ TOMPOROSKI, Alexandre. O pessoal da Lumber: um estudo acerca dos trabalhadores da Southern Brazil Lumber and Colonization Company e sua atuação no planalto norte de Santa Catarina, 1910-1929. Dissertação de Mestrado, UFSC, 2006.p. 19.
} 
gelo, de cigarro, casa bancária, casas comerciais de grande porte, clubes, escola polonesa, colégio de internato, restaurante típico, hotel, cassino e cinema. Era a imagem do progresso instalada na região.

A Brazil Railway Company atuou durante quase trinta anos, sob controle do capital estrangeiro, até sua estatização, assinada por Getúlio Vargas, em plena vigência do Estado Novo, em 22 de julho de 1940. A estatização ocorreu em favor dos "interesses nacionais". Essa foi a justificativa apontada pelo decreto presidencial. A expressão tem um forte viés econômico e financeiro. O fato da Brazil Railway Company e suas filiais controlarem setores de fundamental importância para o Brasil, tais sejam, ferroviário, portuário, energético e de colonização, contribuiu para a estatização. Entretanto, os problemas decorrentes da má gestão nas companhias do grupo Farquhar influenciavam, sobremaneira, a economia nacional. Os atrasos no cumprimento de obrigações com credores de capitais - alavancados em bolsas europeias - geraram descontentamento e abalaram a confiança dos investidores estrangeiros na economia nacional. Isso constrangia a administração pública do país ${ }^{13}$. Com base nessa justificativa, o primeiro artigo do decreto incorporou ao patrimônio da União os bens e direitos tanto da Brazil Railway Company - existentes em território nacional - quanto de suas dependentes, caso da Southern Brazil Lumber and Colonization Company, além de outras onze companhias ${ }^{14}$. Após a incorporação foi nomeado um Superintendente Geral da União e diretores ou gerentes, para as empresas, aos quais coube a representação ativa e passiva da entidade, ficando extintos todos os mandatos de administração que nas mesmas vinham sendo exercidos. Apenas os serviços portuários e ferroviários ficaram subordinados ao Ministério da Viação e Obras Públicas. Os Superintendentes deveriam fazer o levantamento do ativo e do passivo de cada uma das empresas, normalizando a atividade das mesmas, administrando por meio de requisição de recursos e de empregados de cada uma delas, consideradas as suas possibilidades. Terminado o levantamento, deveria ser realizada a liquidação amigável das importâncias que fossem reconhecidas como legais e legitimamente devidas, subordinadas ao Ministro da Fazenda que autorizaria a negociação. Quanto aos lucros obtidos pelas empresas, o Superintendente deveria proceder à verificação do montante, obtidos pela Brazil Railway Company, ou pela Sorocabana Railway Company, Compagnie Francaise du Port de Rio Grande do Sul e Compagnie Auxiliaire de Chemins de Fer au Brésil, com

\footnotetext{
${ }^{13} \mathrm{~A}$ título de exemplo, a Brazil Railway Company encontrava-se sob regime de concordata, a qual não fora homologada pela Justiça brasileira, desde 18 de julho de 1917.

${ }^{14}$ Decreto-Lei n.․ 2.346, de 22 de julho de 1940.
} 
o resgate de obrigações destas últimas por preços inferiores aos que foram pagos pelos cofres públicos, restituindo a estes as importâncias de que foram ilicitamente desfalcadas.

Na região, a estatização da serraria é divulgada na imprensa local como fator de desenvolvimento econômico. As notícias divulgadas à população local inspiravam segurança no que concerne a questão de continuidade no sistema produtivo. Vejamos o teor da matéria:

Está em plena atividade essa grande organisação industrial, cujo nome foi acrescido da palavra "Incorporada". Por acertado e felis ato, do exmo. Snr. Cél. Luiz Carlos da Costa, digno Superintendente das Empresas cujos bens foram incorporados ao patrimônio nacional, permanece à frente da "Lumber", como seu Diretor, o ilustre cavalheiro e nósso distinto amigo snr. Henry Weinmeister, o que é uma garantia da féis continuidade dos trabalhos industriais, sem grandes abalos na economia de Tres Barras e de todo o nosso Município. ${ }^{15}$

Em outro momento, é registrada a questão de investimentos na iluminação pública de Três Barras e de uma nova indústria com apoio da Lumber Inc.:

Fazendo referencia a nota inserida em o n 247 de 1/11/42 deve ficar esclarecido que, a iluminação pública, há longos anos aspirada pela população Tresbarrense, vem se tornando uma realidade, graças ao dinamismo do ilustre sr. cel. Pedro Reginaldo Teixeira, diretor da Cia. Lumber Incorporada, a quem Três Barras deve esse fator de desenvolvimento e progresso motivado pelo seu profícuo e incançavel esforço, contratando a força que movimentará a nova industria que se acha em adiantado estado de construção, o que poderia ter sido feito com os proprios recursos de que dispõe a referida Companhia. ${ }^{16}$

As notícias de desenvolvimento e produção ainda foram divulgadas, no ano de 1943, em matéria intitulada: "Uma visita à maior indústria madeireira da América do Sul." ${ }^{17}$ Inicia a matéria com a descrição do escritório central, onde o mobiliário havia sido reformado; as salas amplas, com sistema de calefação a vapor. O telefone possuía, além dos ramais internos, uma central em comu-

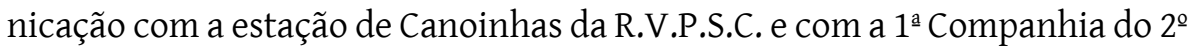
Batalhão Ferroviário, acantonado na Floresta, Distrito de Papanduva. Sobre as demais edificações foram observados dois edifícios, cobertos de telhas, destinados, o primeiro a substituir a fábrica de caixas e cepilhadeira, destruída

\footnotetext{
${ }^{15}$ BARRIGA VERDE. Southern Brazil Lumber and Colonization Company Inc. 01/09 /1940. Ano IV, № 139. Biblioteca Pública do Estado de Santa Catarina (BPESC).

${ }^{16}$ BARRIGA VERDE. Iluminação pública para Três Barras. 08/11/1942. Ano IV, № 248. BPESC.

${ }^{17}$ BARRIGA VERDE. Uma visita a maior indústria madeireira da América do Sul. 01/08/1943. Ano VII, № 243. BPESC.
} 
por um incêndio, e o segundo à fábrica de laminados. Os dois edifícios estavam com o seu maquinário em adiantado estado de instalação, que deveria começar a operar em poucos dias. Haviam sido lançados os alicerces de outro grande pavilhão, destinado à futura fábrica de madeira compensada. No que se refere aos investimentos externos foram realizadas obras de construção de linha férrea, em demanda da Serra do Espigão, onde a Lumber Incorporada, adquiriu pinheirais, que lhe garantia matéria prima, por uma geração ou mais. Outras indústrias subsidiárias foram criadas, tais como: Fábrica de Alcatrão e Carvão, extraídos do nó do pinho com barricaria anexa para a fabricação de vasilhame destinado ao acondicionamento e exportação do produto; laboratório experimental sob a direção de um químico industrial, para o estudo de matéria plástica, ou seja, lâminas de madeira sintética com aproveitamento da serragem; destilaria de petróleo de São Mateus, que havia sido adquirida e ampliada, produzindo gasolina, querosene, óleo combustível e lubrificante, parafina, alcatrão mineral, coke metalúrgico entre outros produtos extraídos do xisto. Em cooperação com o Ministério da Agricultura e supervisão do engenheiro agrônomo Dr. Francisco Bertagnoli Junior, estava sendo instalado em terrenos da Companhia, junto a sede em Três Barras, um campo experimental de vini-fruticultura. Para os trabalhadores, foram substituídos os antigos ranchos cobertos de madeira ou zinco por bangalôs cobertos de telhas, com instalações de água corrente, esgoto e luz. Foi construída a Pensão Restaurante para os trabalhadores. Os operários obrigatoriamente usavam macacão de zuarte, fornecido pelo armazém da empresa a preço de custo com pagamentos em prestações.

Quanto ao número de trabalhadores, de acordo com os registros, ${ }^{18}$ ela contava em 1943 com 809, sendo 732 registrados como empregados substituíveis e 77 como insubstituíveis no prazo de sessenta dias. No que se refere à nacionalidade $85 \%$ eram brasileiros (685), $10 \%$ poloneses (79). Os demais estavam divididos entre europeus da Áustria (10), Alemanha (09), Ucrânia (08), Portugal (07), Rússia (03), Tchecoslováquia (01), Holanda (01), França (01), Lituânia (01) e ainda dos Estados Unidos da América (03) e como ignorada (01). Em se tratando da naturalidade, dos trabalhadores, observamos que dos 809,57\% declaram-se de Santa Catarina (462), 25\% do Paraná (199), 10\% da Polônia (84). Os demais, em menor expressão, estavam divididos entre europeus da Áustria (11), Ucrânia (10), Alemanha (08), Portugal (07), Rússia (03), França (01), Holanda (01), Lituânia (01), Tchecoslováquia (01); dos Estados Unidos da

${ }^{18}$ Relação de Trabalhadores Southern Brazil Lumber and Colonization Company Inc. -1943. Fonte: Acervo do CIMH-Campo de Instrução Marechal Hermes. 
América (3) e de demais regiões brasileiras, sendo do Rio Grande do Sul (05), Bahia (03), Distrito Federal (02), São Paulo (02), Rio de Janeiro (02), Minas Gerais (01), de origem ignorada (02). Na contratação de mulheres, verificamos entre os 809 trabalhadores a presença de sete mulheres, ocupando as funções de datilógrafa, doméstica, enfermeira, farmacêutica e professora. Quanto ao estado civil, eram solteiras com exceção de uma viúva. Apenas a professora era de descendência europeia (Portugal), as demais brasileiras. Na relação de trabalhadores insubstituíveis no prazo de sessenta dias estes desempenhavam as seguintes funções: maquinista (13), foguista (11), manobreiro (09), feitor de guincho (04), mecânico (04), caldeador (03), afiador de serra (02), serrador (02). Os demais estavam registrados em (01) trabalhador por atividade, sendo elas: médico, encarregado de armazém e farmácia, chefe de sessões, farmacêutico, auxiliador de serras, encarregado da serraria, mecânico, encanador, mestre construtor, encarregado do almoxarifado, chefe de oficina, contra mestre, chefe de força e luz, mecânico ajust., mecânico torneiro, ferreiro malhador, ferreiro, torneiro, circuleiro, serrador (reserva), bitoleiro, administrador, sub. administrador, chefe do mato, chefe de locomotiva, maquinista locomotiva, maquinista de guincho, agrimensor. Houve investimentos também no campo de pousos para aviões ${ }^{19}$ e no estádio de futebol ${ }^{20}$.

Em dezembro de 1945, sob direção do Cel. Pedro Reginaldo Teixeira, foi realizado um almoço comemorativo ao quarto ano de sua administração junto a Lumber Incorporada, onde, o Dr. Osvaldo de Oliveira, ${ }^{21}$ discursou além do diretor, transmitindo aos presentes a ideia de progresso e continuidade nas atividades. ${ }^{22}$

A situação jurídica dos trabalhadores foi uma preocupação, tanto dos trabalhadores como dos administradores, como pode ser observado:

Art. $1^{\circ}$ Aos empregados das emprêsas incorporadas ao patrimônio da União ou por esta administradas, serão aplicadas as normas da legislação trabalhista,

\footnotetext{
${ }^{19}$ BARRIGA VERDE. Em Três Barras campo de aviação. 05/12/1943. Ano VII, № 301. BPESC

${ }^{20}$ BARRIGA VERDE. Em Três Barras. 22/04/1945. Ano VIII, № 364. BPESC

${ }^{21}$ De acordo com TOMPOROSKI, Alexandre. O pessoal da Lumber: um estudo acerca dos trabalhadores da Southern Brazil Lumber and Colonization Company e sua atuação no planalto Norte de Santa Catarina, 1910-1929. Dissertação de Mestrado, UFSC, 2006, ele foi delegado da higiene de Canoinhas e Intendente de Três Barras, na década de 1910. Filiado ao Partido Republicano Catarinense, foi Deputado Estadual entre 1919 e 1921 e entre 1925 e 1927. Reeleito em 1926 de forma paralela a prefeitura de Canoinhas, a pedido do Governador de Santa Catarina, no período de 1926 a 1930. Ainda foi eleito vereador de Canoinhas, como representante do Distrito de Três Barras em 1947. No seu segundo mandato, em 1951, devido à morte do prefeito de Canoinhas, Otávio Tabalipa, assume a prefeitura.

${ }^{22}$ BARRIGA VERDE. De Três Barras: Southern Brazil Lumber and Colonization Company Inc. 25/12/1945. Ano XII, № 357. BPESC
} 
quando admitidos antes da incorporação ou administração, e as da legislação sôbre extranumerários da União, se nomeados posteriormente, com os mesmos direitos e vantagens, inclusive aquêles já consagrados sôbre Previdência Social.

Art. $2^{\circ}$ Os dissídios oriundos das relações de trabalho serão resolvidos, quanto aos referidos empregados, para os primeiros, pela justiça do trabalho, e para os segundo, por via administrativa com o recurso para a justiça comum.

Art. $3^{\circ}$ A execução das sentenças preferidas contra as emprêsas de que trata êste decreto-lei seguirá o mesmo rito das execuções contra a Fazenda Pública. Art. $4^{\circ}$ Fica revogado ${ }^{23}$ o parágrafo único do art. $1^{\circ}$ do Decreto-lei número 8.079 de 11 de outubro de $1945^{24}$.

Em correspondência a Gustavo Capanema, o Superintendente das Empresas Incorporadas solicitou apoio para o rápido andamento do projeto $\mathrm{n}$ ㅇ 2.368, que viria a revogar o Decreto Lei acima citado. Sobre este último ele assim refere-se:

Esse projeto, que virá revogar o famigerado Decreto-lei 8.249, de 29/11/1945, responsável pela completa subversão introduzida nos quadros do funcionalismo das Emprêsas Incorporadas e por graves consequências na vida econômica das mesmas, dispõe sobre o destino do pessoal e dá outras providências de caráter salutar..$^{25}$

A partir de 1946 são traçados novos rumos para a Lumber Incorp. Foi autorizada a sua venda, ${ }^{26}$ mediante concorrência pública, das terras situadas nos Estados do Paraná e Santa Catarina; os bens e propriedades da "Brazil Land Cattle and Packing Company"; as propriedades, bens e direitos adquiridos pela Superintendência das Empresas Incorporadas ao Patrimônio da União, durante o período da incorporação, por meio de investimento de capitais.

É interessante observar que, mesmo diante da perspectiva de venda, a serraria continuava com elevada produção. A propaganda ${ }^{27}$ da Lumber Incorporada, divulgada em 1947, revela a diversidade de atividades realizadas pela serraria, citando produção em larga escala de madeiras de pinho e lei,

\footnotetext{
23 "Parágrafo único. Aos trabalhadores ao serviço de empresas industriais da União, dos Estados e dos Municípios, salvo aqueles classificados como funcionários públicos, aplicam-se os preceitos da presente Consolidação."

${ }^{24}$ DECRETO-LEI nº 8.249, de 29 de Novembro de 1945.

${ }^{25}$ CARTA. DO Superintende André Carrazzoni a Gustavo Capanema 23/04/1952. Classificação: GV c 1953.02.27/1 Série: c Data de produção: 27/02 a 09/09/1953 (Data certa) Quantidade de documentos: 8 (26 folhas) Microfilmagem: rolo 15 fot. 0579 a 0590. Arquivo: Getúlio Vargas

${ }^{26}$ Decreto-lei no 9.549 de 06/08/1946.

${ }^{27}$ BARRIGA VERDE. Southern Brazil Lumber and Colonization Company Inc. 01/08/1947. Ano XII, № 477. BPESC.
} 
caixas desarmadas de todos os tipos, laminados e compensados, tacos e imbuia, soalho e forros, casas desmontadas, móveis, etc.

A possibilidade de venda fez com que o governo adotasse algumas medidas. Pela Lei $n^{\circ} 253$ de 18/02/1948 ${ }^{28}$, o Ministério da Fazenda abre um crédito especial de cento e cinquenta e um milhões de cruzeiros (Cr\$151.000.000,00) correspondentes a dois milhões de libras $(£ 2.000 .000,00)$, ao câmbio de setenta e cinco cruzeiros e cinquenta centavos ( $\mathrm{Cr} \$ 75,50)$, para indenização (Serviços e Encargos) aos acionistas das Empresas Incorporadas no Patrimônio da União da Southern Brasil Lumber and Colonization Company, da Companhia Indústrias Brasileiras de Papel, Empresa de Armazéns Frigoríficos, autorizando ainda, a venda, mediante concorrência pública, das referidas empresas.

Foi desmembrada parte do patrimônio da Southern Brasil Lumber and Colonization Company Incorporada e administrada separadamente, compreendendo a fazenda "Morungava", com área aproximada de 36.000 alqueires (a $24.200 \mathrm{~m}^{2}$ por alqueire), com instalações industriais, reservas florestais, etc. Esta parte foi vendida em 1948 ao preço de Cr $\$ 21.000 .000,00$, aproximadamente, incluídas as reservas florestais. Em 17 de março de 1949 foi colocada a venda o restante do patrimônio da Lumber, pelo valor básico de Cr\$50.000.000,00. 0 prazo de aquisição foi diversas vezes prorrogado. 0 acervo era constituído por um extenso rol de bens, dentre os quais: uma propriedade em Calmon, com quinze mil alqueires ${ }^{29}$ de terras e trezentos e cinquenta mil pinheiros adultos; na região da Serra do Espigão, então município de Canoinhas, outros duzentos mil pinheiros adultos; remanescentes de 'propriedades loteadas', entre os quais muitos lotes que haviam sido vendidos entre as estações ferroviárias de Canivete e Valões (atual Irineópolis); um terreno com mais de dez mil metros quadrados, em São Francisco do Sul; na região da Barra Funda, em São Paulo, um "palacete", quatro casas menores e um terreno com dez mil metros quadrados; uma propriedade com seiscentos e cinquenta alqueires no então Distrito canoinhense de Papanduva (atual município de Papanduva); um terreno - com cerca de nove alqueires - onde estava instalada a serraria, fábrica de caixas, laminadora, oficinas, casas, armazéns, e hospital; aproximadamente quarenta e três quilômetros de linha férrea assentada, além de maquinário da indústria de madeira, locomotivas, cerca de quarenta vagões e plataformas para transporte de madeira pela ferrovia. ${ }^{30}$

\footnotetext{
${ }^{28}$ Lei no 253 de 18/02/1948.

${ }^{29} \mathrm{Um}$ alqueire representa na região sob análise, 2,42 hectares.

${ }^{30}$ Diário do Congresso Nacional. Brasília, 23 de maio de 1953. p.4374.
} 
No Diário Oficial da União, de 22 de setembro de 1950, foi publicada a proposta de três firmas para aquisição dos bens restantes da Lumber Incorp..

[...] 1ํ -"Pinho e Terras, Ltda.", pagará pelos imóveis e benfeitorias existentes na cidade de São Paulo, estado de São Paulo, de Jaguaraiva, Guarapuava e Paranaguá, sitas no Estado do Paraná, a importância de Cr\$1.500.000,00 (um milhão e quinhentos mil cruzeiros) no ato da escritura pública de compra e venda ou nas condições da letra d. do Decreto-Lei nº 9.658, de 23 de agosto de 1946, a opção da proponente. A escritura pública de compra e venda deverá ser assinada no prazo de noventa (90) dias contados da data de aprovação desta proposta, em favor do proponente ou de quem esta indicar.

$2^{\circ}$ - as sociedades “Pinho e Terras Ltda." e Indústrias Gropp S.A.", solidariamente, pagarão pelo imóvel denominado "São Roque, descritos no edital de concorrências, com as reservas florestais, benfeitorias, instalações, estoque, inclusive 19 (dezenove) vagões, plataforma, freio a vácuo, nele existente e de "porteiras fechadas" a importância de Cr $\$ 8.550 .000,00$ (oito milhões, quinhentos e cinquenta mil cruzeiros), no ato da assinatura da respectiva escritura pública de compra e venda, ou nas condições da letra d. do Decreto-Lei nº 9.658, de 23 de agosto de 1946 a união das sociedades proponentes. A escritura pública de compra e venda será assinada no prazo de cento e vinte (120) dias contados da data de aprovação desta proposta, em favor do proponente ou de sociedade que venham a constituir, ou ainda, de quem indicarem.

3-- A sociedade "Companhia de Madeiras Del Alto Paraná S.A." pagará pelos restantes bens da "Southern Brasil Lumber and Colonization Company Incorporada”, ou seja, pelos imóveis situados em Três Barras; Valões e São Francisco, estado de Santa Catarina com tôdas as suas benfeitorias, instalações industriais, maquinaria, estrada de ferro, estoques, etc. e reservas florestais existentes nos mencionados territórios, na Serra do Espigão e opções de compra tudo conforme descrição dos editais de concorrência a importância de $\mathrm{Cr} \$ 40.050 .000,00$ (quarenta milhões e cinquenta mil cruzeiros), pagamento que será nas condições da letra d. do Decreto-Lei no 9.658, de 23 de agosto de 1946. A escritura pública de compra e venda será assinada no prazo de cento e oitenta (180) dias contados da data de aprovação desta proposta, em favor da firma ou de sociedade que venham a constituir, ou que indique devendo, preliminarmente ser conferido com a presença de representantes da proponente, uma relação e inventários dos estoques registrados nos livros da sociedade à venda, existentes nos escritórios da mesma, no lugar denominado "Três Barras", tudo nos termos dos editais de concorrência.

$4^{\text {-- }}$ Os proponentes receberão todos os bens da presente proposta, livres de desembaraçados de quaisquer ônus e contestações respondendo a vendedora pela devolução. ${ }^{31}[. .$.

${ }^{31}$ Diário do Congresso Nacional. Brasília, 22 de setembro de 1950. p.13943. 
As três empresas, Cia. Terra e Pinho Ltda., Groppe S.A., Cia. Madeiras Del Alto Paraná, eram controladas pelo mesmo indivíduo, Alberto Dalcanale, ${ }^{32}$ empresário que atuou na colonização do Sudoeste do Paraná e Oeste de Santa Catarina.

No mês de março de 1951, um representante da $5^{a}$ Região Militar, cuja sede do comando localizava-se em Curitiba, procurou o governo do estado de Santa Catarina visando obter apoio para identificar uma área de terras entre três e quatro mil alqueires. Tal área deveria estar localizada nas proximidades da Lumber, em Três Barras, entre os rios Canoinhas, São João e Rio das Antas. Em correspondência ao comandante da $5^{\mathrm{a}}$ Região Militar, à época o General Tristão de Alencar Pires, o governador catarinense, o udenista Irineu Bornhausen, manifestou enlevo pela ideia, segundo ele, "visando o progresso que advirá para Três Barras com o estabelecimento, ali, de uma Unidade do Exército Nacional". ${ }^{33}$ O governador enviou instruções ao prefeito municipal de Canoinhas, orientando-o para que, juntamente com o representante da Companhia de Madeiras Del Alto Paraná, empresa compradora do acervo da Lumber, compusesse uma comissão com o objetivo de localizar uma área de terras que atendesse aos interesses dos militares.

Transcorrido pouco mais de um mês, em nova correspondência do governo catarinense destinada ao comando da $5^{\mathrm{a}}$ Região Militar, o chefe do executivo estadual ratificou sua intenção em colaborar com os interesses dos militares, acerca da instalação do campo de manobras no município de Canoinhas. $\mathrm{O}$ entusiasmo de Irineu Bornhausen com a negociata levou-o a declarar que estava “(...) disposto a tomar todas as providências no sentido de desapropriar as terras necessárias à instalação, no município de Canoinhas, do Campo de Instruções e Manobras da 5 $5^{\text {a }}$ Região Militar, na área escolhida pela Comissão designada por esse comando" ${ }^{34}$. Dessa forma, o então governador do estado de Santa Catarina, delegou a responsabilidade pela escolha de uma área de terras a uma comissão constituída por representantes do Ministério da Guerra e pelo controlador das empresas que haviam adquirido os bens que integravam o acervo da antiga Lumber. Nesse contexto, estranha o fato dessa atribuição para escolher e desapropriar terras ter sido transfe-

\footnotetext{
${ }^{32}$ Diário do Congresso Nacional. Brasília, 23 de maio de 1953. p.4374.

${ }^{33}$ Ofício N. 85 - Florianópolis/SC, 12 de março de 1951. Do Governador do Estado de Santa Catarina ao Comandante da $5^{a}$ Região Militar. Correspondências e Minutas do Palácio do Governo de Santa Catarina para o Ministério da Guerra. APESC (Arquivo Público do Estado de Santa Catarina).

${ }^{34}$ Ofício N. ${ }^{\circ} 161$ - Florianópolis/SC, 20 de abril de 1951. Do Governador do Estado de Santa Catarina ao Comandante da $5^{a}$ Região Militar. Correspondências e Minutas do Palácio do Governo de Santa Catarina para o Ministério da Guerra. APESC.
} 
rida a uma comissão que apresentava, entre seus membros, representantes de empresas privadas.

Na mesma correspondência, o governador Irineu Bornhausen, com o objetivo de "reduzir os custos com as indenizações" decorrentes das desapropriações, apresentou uma proposta para permuta das novas áreas de terras, que seriam desapropriadas pelo estado catarinense, com áreas de terras outrora pertencentes à antiga Lumber, transferidas ao Ministério da Guerra após a estatização daquela companhia. O General Tristão, atônito, afirmou não ter compreendido a proposta, afinal, segundo ele, o patrimônio total da Lumber, elencadas as terras, instalações e reservas florestais, estaria avaliado em cinquenta milhões de cruzeiros, enquanto as áreas de terrenos que o exército receberia, caso aquiescesse com a permuta, “embora mais extensas, são, porém, de valor incomparavelmente bem mais reduzido do que aquelas terras da Lumber". A tentativa do governador catarinense em ludibriar o Ministério da Guerra, através de uma ardilosa proposta de permuta fundiária, foi prontamente rechaçada pelo comando militar. Contudo, esse revés nos planos para utilização do acervo da Lumber em prol de interesses privados, não significou o abandono do projeto.

No dia 29 de maio de 1951, foi realizada uma reunião da Comissão Regional de Escolha de Imóveis para o Ministério da Guerra, na sede da Lumber Incorp. em Três Barras, município de Canoinhas ${ }^{35}$. Entre os presentes, encontravam-se os militares componentes da Comissão ${ }^{36}$, os delegados da Superintendência das Empresas Incorporadas ao Patrimônio Nacional ${ }^{37} \mathrm{e}$ os representantes da Companhia de Madeiras Del Alto Paraná..$^{38}$

O empresário Alberto Dalcanale declarou abrir mão, em favor do Ministério da Guerra, de área sob controle da Cia. de Madeiras do Alto Paraná, situada na região compreendida entre os rios Canoinhas, Jangada, Papanduva, bem como de glebas situadas nas regiões de Valões, São João da Barra e Toldo de Cima, "exceção feita da área de reflorestamento da gleba de Valões”. Dalcanale concordou com a transferência integral das instalações e maquinarias existentes na sede da Lumber, em Três Barras, ao Ministério da

\footnotetext{
${ }^{35}$ Ata da Reunião realizada pela Comissão Regional de Escolha de Imóveis para o Ministério da Guerra. Três Barras, município de Canoinhas, 29 de maio de 1951. APESC.

${ }^{36}$ General Sady Martins Vianna, Tenentes Coronéis Carlos Queiros Falcão e Murat Guimarães, Capitães Basílio Marques dos Santos Sobrinho e Dr. José Alvarenga Moreira, sob a presidência do primeiro.

${ }^{37}$ Hortencio Alcantara Filho e Ary d'Leary Paes Leme.

${ }^{38}$ Alberto Dalcanale e Wilen B. Martins.
} 
Guerra. ${ }^{39}$ Evidentemente, as cessões dos bens não foram motivadas por um patriotismo exacerbado por parte de Dalcanale. A transferência das áreas supracitadas (com exceção feita àquelas povoadas por pinheiros) consistiu em um estratagema que objetivou desatar os bens de menor valor e transferir os trabalhadores da antiga Lumber para uma instância pública - no caso, o Ministério da Guerra - desincumbindo as empresas de Dalcanale das obrigações referentes aos salários, encargos trabalhistas e de contingências resultantes de indenizações aos operários da companhia incorporada.

Após a efetivação da transferência, prosseguiram as negociações para a doação, pelo governo catarinense, de terrenos que complementariam a área necessária para instalação de um campo militar. O governador de Santa Catarina, Irineu Bornhausen, propôs uma solução, aceita pelo então Ministro da Guerra, General Henrique Teixeira Lott, que consistiu na utilização dos recursos consignados na emenda n.. 157 , no montante de $\operatorname{Cr} \$ 40.000 .000,00$ (quarenta milhões de cruzeiros), para fins de complementação da dotação orçamentária do Ministério da Guerra, visando prover recursos para pagamento das indenizações decorrentes das desapropriações de terras necessárias à composição do campo militar em Três Barras. ${ }^{40}$ Portanto, a atuação de Bornhausen foi decisiva para a instalação do campo militar, inclusive dispondo-se a desapropriar novas áreas de terra necessárias à composição do campo, o que, de fato, consistiu num compromisso formal, contudo destituído de ônus para o governo catarinense. Os empecilhos à maximização dos lucros das empresas controladas por Dalcanale haviam sido removidos, incrementando a expectativa de auferir vantagens - lícitas ou não - àqueles que apoiaram ou contribuíram decisivamente para o desfecho do negócio.

Após a reunião realizada em Três Barras, e, por conseguinte, do desenlace dos trâmites jurídicos, a partir do dia 11 de setembro de 1952, a área onde outrora funcionara a Southern Brazil Lumber and Colonization Company foi transferida ao controle do exército brasileiro, dando origem ao CIMH - Campo Instrução Marechal Hermes, sob comando da $5^{\text {a }}$ Região Militar de Curitiba.

\footnotetext{
${ }^{39}$ Ofício n. .913 . Florianópolis/SC, 31 de julho de 1957. Do Governador do Estado de Santa Catarina - Jorge Lacerda - ao Comandante da $5^{a}$ Região Militar - General Aurélio Lyra Tavares. Além do Superintendente das Empresas Incorporadas ao Patrimônio da União, a reunião de transferência teve a presença de um representante do Ministério da Guerra, membros da Comissão de Levantamento e Avaliação, representante do governo catarinense e dos compradores dos bens da Lumber, "tudo de conformidade com os entendimentos havidos entre o Ministério da Guerra, a Superintendência, os adquirentes do acervo da Lumber e o Estado de Santa Catarina.

${ }^{40}$ Ofício n. 913. Florianópolis/SC, 31 de julho de 1957. Do Governador do Estado de Santa Catarina - Jorge Lacerda - ao Comandante da $5^{\mathrm{a}}$ Região Militar - General Aurélio Lyra Tavares.
} 
Aqueles bens que exibiam potencial para otimizar a geração de lucros - dentre os quais uma ingente propriedade em Calmon, a fazenda São Roque, com duas serrarias, desvios ferroviários, trezentos e cinquenta mil pinheiros, imbuias, etc., edifícios em São Paulo e Paraná e vastos pinheirais na Serra do Espigão, em Santa Catarina - permaneceram sob controle das empresas adquirentes controladas por Alberto Dalcanale, e sua exploração gerou, imediatamente, acentuado retorno econômico-financeiro. Em contrapartida, a serraria de Três Barras - transferida por Dalcanale ao Ministério da Guerra - permanecia praticamente imobilizada, analogamente ao grupo de antigos trabalhadores da Lumber, que ficara sob responsabilidade do exército. Os custos estimados para amortização dos encargos decorrentes de eventuais demissões dos trabalhadores poderiam atingir a cifra de quinze milhões de cruzeiros. ${ }^{41}$

Ainda no decorrer do ano de 1953, o então Deputado Federal Saulo Ramos, apresentou um relatório - que fora submetido a uma Comissão Parlamentar de Inquérito - no qual detalhou as irregularidades envolvendo a Lumber Company. O relatório sustentava que a Companhia Pinho e Terras Ltda, detentora da propriedade Calmon, com cerca de 350 mil pinheiros, além dos três edifícios na região da Barra Funda, em São Paulo, cujos preços atingiam o montante de $\mathrm{Cr} \$ 8.500 .000,00$ (oito milhões e quinhentos mil cruzeiros), imediatamente após a concretização da negociação, realizou a venda dos imóveis localizados na Barra Funda, recebendo a importância de Cr\$10.000.000,00 (dez milhões de cruzeiros). Sem dúvida um excelente negócio. Além disso, as centenas de milhares de pinheiros possuíam valor estimado entre $\mathrm{Cr} \$ 100 \mathrm{e}$ Cr $\$ 200$ (cem e duzentos cruzeiros) a unidade, ou seja, após seu corte e venda, também poderiam auferir lucro de dezenas de milhões de cruzeiros. ${ }^{42}$

À empresa Groppe S.A., coube a parcela industrial do acervo, além de faixas de terras marginais à Rede Viação Paraná Santa Catarina. Esses consistiram nos itens do acervo que posteriormente foram transferidos ao Ministério da Guerra. A terceira empresa que compunha o consórcio, a Cia. De Madeiras Del Alto Paraná S.A., obteve os pinheirais da Serra do Espigão, uma propriedade na localidade de Felipe Schmidt, município de Canoinhas, e uma área de dez mil metros quadrados, em São Francisco do Sul.

0 referido relatório estimava que o valor real dos bens e direitos da Lumber atingiria o montante de $\mathrm{Cr} \$ 100.000 .000,00$ (cem milhões de cruzeiros).

\footnotetext{
${ }^{41}$ BARRIGA VERDE. Em defesa dos trabalhadores. Discurso proferido da Tribuna da Câmara na sessão de 17/03/1954 pelo Deputado Leoberto Leal. 24/03/1954. Ano XVII № 839. BPESC.

${ }^{42}$ Diário do Congresso Nacional. 23 de maio de 1953. p. 4390.
} 
No entanto, o preço básico fora definido em apenas $\mathrm{Cr} \$ 50.000 .000,00$ (cinquenta milhões de cruzeiros). Segundo o relatório, o preço dos pinheiros e das propriedades fora subavaliado, em valores aquém das cotações do mercado, na mesma época e nos mesmos locais.

Ao tomar conhecimento do interesse do Ministério da Guerra em compor um campo militar na região de Três Barras, o proprietário das três empresas consorciadas que adquiriram os bens da Lumber, Alberto Dalcanale, prontificou-se em ceder a propriedade de seiscentos e cinquenta alqueires, além da parte industrial, maquinários, ferrovia, edifícios e algumas propriedades em São Francisco do Sul. Certamente, um notório empresário do setor fundiário, madeireiro e colonizador, não obtinha fortuna realizando doações motivadas por seu patriotismo. Juntamente com a parcela do acervo, de interesse do exército, Dalcanale transferiu os duzentos e sessenta e quatro trabalhadores da Lumber e os correspondentes encargos trabalhistas. $O$ jornal Barriga Verde, em março de 1953, denunciou aquilo que definiu como "uma das mais negras manobras para saquear a Fazenda Nacional". Segundo o jornal, os dirigentes das Empresas Incorporadas ao Patrimônio da União e os compradores do acervo da Lumber Company, entre eles Irineu Bornhausen, então governador do estado de Santa Catarina, pressionaram o Ministério da Guerra para que assumisse os encargos trabalhistas, objetivando isentar os compradores do acervo ${ }^{43}$.

No dia 04 de fevereiro de 1954, a filha de Alberto Dalcanale, Ivete Terezinha, e o filho do governador Irineu Bornhausen, Paulo Konder Bornhausen, contraíram matrimônio. Enquanto as famílias Dalcanale e Konder Bornhausen celebravam sua união por intermédio do casamento de Paulo e Ivete, os duzentos e sessenta e quatro trabalhadores da Lumber e suas famílias, num total de aproximadamente mil e duzentas pessoas, padeciam com o segundo período de atrasos no recebimento dos salários. Surgiam os "flagelados de Três Barras".

\subsection{Das manifestações dos trabalhadores}

O acervo da antiga Lumber foi alvo de negócios espúrios. O processo de encampação dos bens pertencentes à Lumber Company esteve envolto em irregularidades, escopo de estratagemas que objetivavam a divisão dos bens. Os bens que integravam o acervo foram vendidos em concorrência pública,

\footnotetext{
${ }^{43}$ Barriga Verde. A alienação dos bens da "Lumber Incorporada" constitui das mais negras manobras para saquear a Fazenda Nacional. 19/03/1953. Ano XVI № 752. BPESC.
} 
por valores muito aquém daqueles vigentes no mercado, em desobediência ao edital. Aqueles bens que apresentavam valores vultosos foram desmembrados, e a serraria de Três Barras, que em determinada época fora a maior da América do Sul, uma das maiores do mundo, tornou-se obsoleta, além de padecer com a escassez de matéria prima em seu entorno.

Diante da situação de indecisão na venda do patrimônio da Lumber os trabalhadores encaminham, em 15/10/1951, um abaixo-assinado, sob a forma de carta, a Getúlio Vargas expondo a situação dos bens patrimoniais da empresa e propondo a aquisição da serraria de Três Barras (SC) ou a formação de uma sociedade de economia mista com a União. Nesta correspondência, contendo 49 assinaturas, eles relatam que a empresa teve suas atividades paralisadas a partir de 23 de julho de 1949 devido à falta de matéria-prima. Justificaram a falta de matéria-prima para a produção própria, para venda, ou para manufaturas de caixas, como decorrente da venda da propriedade de "São Roque", localizada em Calmon-SC, citando na carta:

Em consequência desta paralização foram dispensados, recebendo as indenizações de acordo com a Legislação Trabalhista, mais de quatrocentos (400) operários e funcionários com menos de dez anos de serviço na Êmpresa, permanecendo todos os servidores com mais de 10 anos de serviços e mais alguns, para preencher os quadros indispensáveis ao funcionamento normal das oficinas em funcionamento, estes com menos de 10 anos de serviço. [...] Existem, entre os operários e funcionários da Emprêsa (Lumber), inúmeros que trabalham há 20, 30 anos e mesmo alguns desde o ano de $1910^{44}$.

Preocupados com o futuro incerto, os trabalhadores propõem a aquisição dos bens do item três da proposta de compra divulgado no Diário Oficial da União de 22/09/1950, caso não cheguem a bom termo as negociações até então não concluídas. Segue transcrição da proposta.

$1^{\circ}$ parte, liquidável com os direitos de estabilidade, devida e legalmente computados; o saldo, pagável em prestações, prazos a estabelecer. Valor básico: - conforme a escrituração ou a ser estabelecida.

$2^{\mathrm{a}}$ ou alternativamente a formação de uma Sociedade Anônima, mixta com a União, transformados em capital- ações os bens existentes. Parte dessas passariam aos funcionários em pagamento dos seus direitos de estabilidade e o restante ficaria a cargo da União.

${ }^{44}$ CORRESPONDENCIA. Abaixo assinado dos trabalhadores da Lumber. Arquivo: Getúlio Vargas Classificação: GV c 1951.10.15/2 Data: 15/10/1951 Qtd.de documentos: 1 (13 fl.) 
A parte técnica da administração seria confiada aos servidores da Emprêsa eleitos para tal fim. A União teria como seu representante um Diretor com funções de fiscalização geral sobre as atividades da Emprêsa. ${ }^{45}$

Os duzentos e sessenta e quatro trabalhadores da Lumber Company que se encontravam em atividade quando da estatização da companhia foram transformados em moeda de troca pela Superintendência da União, pelo Ministério da Guerra e, principalmente, pelos compradores do acervo da empresa. Todas as partes envolvidas nas negociações fizeram o possível para se livrarem da responsabilidade sobre os trabalhadores, seus encargos trabalhistas e indenizações decorrentes de eventuais demissões.

Após a transferência do segmento industrial da Lumber ao Ministério da Guerra, ocorrida em julho de 1952, foi firmado um acordo entre as partes interessadas, através do qual concordaram que as obrigações salariais do pessoal da Lumber seriam arcadas pela Superintendência da União, até que o Ministério da Guerra detivesse verbas para essa finalidade.

No entanto, a partir do mês de setembro de 1952, cessaram os pagamentos dos salários, momento a partir do qual as duzentas e sessenta e quatro famílias de trabalhadores da Lumber Incorporada iniciariam uma longa e angustiante jornada, cuja primeira etapa duraria. A maioria dos trabalhadores recebia salários situados na faixa entre $\mathrm{Cr} \$ 600,00$ (seiscentos cruzeiros) e $\mathrm{Cr} \$$ 900,00 (novecentos cruzeiros).

Os trabalhadores admitidos antes da sua absorção pelo governo, encaminharam correspondência, ao presidente da república, Getúlio Vargas solicitando que fosse apressada a aprovação do projeto de Lei 181, de 1951, em andamento na Câmara dos Deputados, de autoria do deputado Celso Peçanha, que visava assegurar-lhes os benefícios do salário-mínimo. Eles necessitavam da revogação parcial do Decreto-Lei 8.249, pois havia criado desigualdade no que diz respeito ao salário família instituído pelo Decreto Lei 5.976 de 10 de novembro de 1943, o qual era concedido a uns e negado a outros, todos empregados na mesma empresa, apenas tendo a distingui-los o divisor de águas representado pelo ato de incorporação ou de administração nacional. A correspondência datada de 11 de dezembro de 1952 foi encaminhada contendo 618 (seiscentos e dezoito) assinaturas. ${ }^{46}$

${ }^{45}$ CORRESPONDENCIA. Abaixo assinado dos trabalhadores da Lumber. Arquivo: Getúlio Vargas. Classificação: GV c 1951.10.15/2 Data: 15/10/1951 Qtd.de documentos: 1 (13 fl.)

${ }^{46}$ CORRESPONDENCIA. Dos trabalhadores das Empresas Incorporadas ao Patrimônio Nacional ao presidente Getulio Vargas. Arquivo: Getúlio Vargas. Classificação: GV c 1952.12.11/07 Data: 11/12/1952 Qtd. de documentos: 3 (18 fls.) 
Em março de 1953 eles já estavam com sete meses de salários atrasados. Um grupo de senhoras encaminhou telegrama ao excelentíssimo Cardeal Dom Jayme Câmara, nos seguintes termos:

Esposas 263 empregados antiga Empresa Southern Brazil Lumber ora transferida
Ministério Guerra apelam magnânimo coração vossa eminência interceder
pessoalmente junto Presidente da Republica sentido ser-lhes pago vencimentos
atrazados desde setembro último vg. Responsabilidade superintendência
Empresas Incorporadas pt Serviço Subsistencia Militar Quinta Região não mais
poderá fornecer generos primeira necessidade até agora abastecia população
superior mil almas cerca metade composta crianças pt Estoque gêneros
armazém local prestes exgotar-se alem falta necessário enfrentar rigoroso
inverno esta região inicio mês abril pt Apêlos feitos há dois meses chefes
partidos PTB PSD inclusive memorial entregue senhor Presidente Republica
sua visita Curitiba sem resultado algum até momento pt por Jesus Christo vinde
nossos socorro antes nossos esposos sejam levados situação desespero pt Por
Deus não nos desampare Nosso pároco reverendísssimo Frei Elisiário poderá
informar situação angustia pavor de nossas almas. ${ }^{47}$

Para complicar a situação, devido ao não repasse dos descontos obrigatórios para órgãos de previdência social (I.A.P.I. e I.P.A.S.E.) os trabalhadores ficaram impossibilitados de recorrer a estas caixas para obtenção de empréstimos.

No ano de 1953 o superintendente André Carrazzoni, relatou ${ }^{48}$ ao presidente da república Getúlio Vargas a crise financeira das empresas incorporadas ao patrimônio nacional. Solicita a interferência do presidente junto ao Banco do Brasil para facilitar empréstimo para os compromissos inadiáveis. Lembrou que tinha créditos a receber relativo à venda da Fábrica de Papel de Arapoti, dos pinheiros remanescentes da Lumber, mas precisava resolver o empecilho de contratos realizados por administrações anteriores, o que levaria de cinco a seis meses e a gleba das Missões e Chopin, não podendo operar sobre elas devido ao arbitramento do governo do Paraná. Comunicou que o ativo recebido foi se exaurindo, e quanto aos bens, nada mais restava a alienar. Recordou que recebeu autorização para empréstimos de 50 milhões de cruzeiros, não tendo sido negociada a espera da aprovação da Câmara. Solicitou que se abrisse crédito de 15 milhões em caráter de urgência e contava com apoio dos diferentes segmentos políticos como o líder Gustavo Capanema, reclamando da demora de aprovação de projetos que poderiam solucionar a crise financeira.

\footnotetext{
${ }^{47}$ BARRIGA VERDE. Os flagelados de Três Barras suplicam a Jesus Cristo. Cardeal Dom Jayme Câmara, 15/03/1953. Ano XVI № 751. BPESC.

${ }^{48}$ CORRESPONDÊNCIA, 27/03/1953. Carta do superintendente André Carrazzoni para o presidente da Republica Getúlio Vargas. Classificação: GV c 1953.02.27/1 (Folhas 01-02) Microfilmagem: rolo 15 fot. 0579 a 0590
} 
Na sessão da Câmara de Vereadores de Canoinhas ${ }^{49}$, Carlos Schermann apresentou indicação no sentido de se conseguir auxilio do município para que uma comissão de operários pudesse ir a capital do país afim de reclamar o pagamento a que tinham direitos, já com atraso há quase onze meses.

Em 30/12/1953 de conformidade com a Lei no 2.150 foi aberto crédito especial de $\mathrm{Cr} \$ 6.508 .289,30$ e efetuado o adiantamento de $\mathrm{Cr} \$ 4.023 .810,30$, destinados ao pagamento dos salários em atraso. Os recursos exauriram-se e os atrasos foram uma constante. Os pagamentos retroativos foram realizados somente no mês de dezembro de 1953. A representação política regional manifestou-se diante do novo atraso de pagamento. o Deputado Estadual Leoberto Leal, em defesa aos trabalhadores proferiu discurso na tribuna da Câmara, em sessão de 17/03/1954.

[...] É de desolação o estado que chegou o patrimônio entregue ao Exército, e a situação do pessoal civil é absolutamente insustentável. [...] Depois de muitas démarches,com o comandante do Campo eu, os Deputados Saulo Ramos e Wanderley Júnior e o Senador Ivo d'Aquino, obtivemos da boa vontade do ilustre Ministro Oswaldo Aranha, um adiantamento de quatro milhões de cruzeiros, por conta de um crédito especial de seis milhões e meio a ser votado ao Ministério da Guerra, para o atendimento dos salários atrazados dos servidores da Lumber. Esse pagamento, ocorrido em agosto, impediu os "flagelados de Três Barras", já então no limite da resistência física, cessarem de sofrer, naquela ocasião. Não perderem, entretanto, por esperar, aquêles velhos trabalhadores do Brasil, pois o sofrimento recomeçou logo depois... Apesar de votado o crédito em regime de urgência, pela lei n 2.150, de 30.12.1953, até hoje não foi entregue o saldo no montante de $\mathrm{Cr} \$ 2.509 .289,30$ ao Ministério da Guerra, para pagar os salários dos meses de setembro a dezembro de 1953 [...]. ${ }^{50}$

Sobre a realidade dos trabalhadores foi ainda, ressaltado no discurso do Deputado:

Permita-me o Plenário que eu trace ligeiramente a situação de calamidade em que se debatem os 246 empregados da antiga Lumber, hoje servindo no Campo Militar. Eles com suas famílias, ao todo mais de 1.200 pessoas, não dispõem mais de dinheiro e nem de crédito para prover aos alimentos e ao vestuário. E faltam apenas três meses para que se inicie o inverno, rigoroso naquelas paragens. A Subsistência Militar da 5 $5^{\mathrm{a}}$ Região, suspendeu há muito os fornecimentos, de maneira que está vazio o armazém do Campo. Os poucos gêneros que o Comando da Unidade consegue adquirir com as Economias Administrativas, chega apenas

${ }^{49}$ A Câmara de Vereadores manifestou-se em prol da crise dos trabalhadores da Lumber, tendo registros nas Atas das sessões: (02/06/1952), (25/08/1953), (23/05/1955), (06/11/1955), (31/05/1955), (07/06/1955), (17/11/1955), (17/02/1956).

${ }^{50}$ BARRIGA VERDE. Os flagelados de Três Barras suplicam a Jesus Cristo. Cardeal Dom Jayme Câmara, 15/03/1953. Ano XVI № 751. BPESC. 
para um fornecimento que atinge às raias do inacreditável. Conversei com donas de casa, de família numerosa, que me descreveram o seu desespero. Recebem elas um quilo de arroz, alguns quilos de trigo e nada mais. Dinheiro não têm para procurar o comercio local e ninguém mais lhes fia um cruzeiro [... $]^{51}$.

Os trabalhadores encaminharam correspondência ao presidente da República sugerindo uma possível solução, no sentido de terem seus direitos amparados. Vejamos a proposta:

[...] 1ํ Autorização em caráter de urgência de um adiantamento por conta da verba em crédito especial, a ser pedido pelo Ministério da Guerra, para pagamento dos vencimentos em atraso do pessoal civil do Campo de Instrução "Mal. Hermes", de forma que esse pagamento possa ser efetuado antes do natal de 1955.

2º Concessão de um crédito especial ou verba, que venha garantir a continuidade do pagamento dos mesmos servidores, até a solução definitiva de sua situação. $3^{\circ}$ Recomendar aos órgãos responsáveis o apressamento da solução final da situação do pessoal civil atualmente lotado no Campo de Instrução "Mal. Hermes", tanto na parte que se refere aos extranumerários, como pelos amparados pela Consolidação das Leis do Trabalho, ou melhor especificando:

a)Proceder a distribuição entre os diversos Ministérios, dos servidores extranumerários, desnecessários aos serviços do campo de instrução "Mal. Hermes", dispensando e indenização os demais amparados pelas Leis do Trabalho, de conformidade com a sentença proferida pela Justiça do trabalho da Comarca de Canoinhas, em 29 de outubro de 1954;

b) Ou ainda mandando tornar aplicável ao pessoal civil do Campo de Instrução Militar “Mal. Hermes", a Lei no 2.193 de 9 de março de 1954, considerando terem os mesmos servidores sido transferidos da Superintendência das Emprezas Incorporadas ao Patrimônio Nacional, para o Ministério da Guerra, sem a devida publicação das respectivas tabelas numéricas e nominais, lhes permitindo dessa forma, optar pela continuação nos serviços da União, como extranumerários, para posterior distribuição pelos diversos Ministérios, ou indenizados na conformidade da Legislação do Trabalho, aos que assim preferirem [...]. ${ }^{52}$

Pelo teor da correspondência constata-se de que os trabalhadores estavam organizados, informados e orientados dos seus direitos e possibilidades de solução para o caso.

Em janeiro de 1956 o presidente da Câmara Municipal de Canoinhas, Generoso de Almeida, acompanhado do Deputado Leoberto Leal e do Sr. Orty de Magalhães Machado, foi recebido pelo presidente da República Nereu

\footnotetext{
${ }^{51}$ BARRIGA VERDE. Em defesa dos trabalhadores. Discurso proferido da Tribuna da Câmara na sessão de 17/03/1954 pelo Deputado Leoberto Leal. 24/03/1954. Ano XVII № 839. BPESC.

${ }^{52}$ BARRIGA VERDE. Desesperado apelo dos servidores da antiga Lumber ao presidente Nereu Ramos para que socorra em sua dramática situação. 25/12/1955. Ano XIX № 1006. BPESC.
} 
Ramos e pelo Ministro de Guerra General Lott. Na oportunidade foi exposta a situação do pessoal civil do Campo Militar Marechal Hermes, antigos servidores da Lumber. O General Lott determinou ao seu chefe de Gabinete, general de Brigada Antonio José Coelho dos Reis, a feitura de nova exposição de motivos na qual pedia a abertura de novos créditos especiais para pagamento dos atrasados, propondo também a indenização aos trabalhadores..$^{53}$

Em 1956 os trabalhadores já estavam com onze meses de salários atrasados. O Deputado João Colodel, líder da bancada do PTB na Assembleia Legislativa, interpela o então candidato a presidência da República, Juscelino Kubitscheck, quando de sua passagem por Canoinhas, sobre o compromisso do pagamento em caso de ser eleito, além de levantar o caso na Assembleia em 05 de março de 1955. Diante do seu requerimento, foi encaminhado um longo telegrama ao presidente e vice-presidente do país clamando por uma solução urgente. ${ }^{54}$

Dona Sybila ${ }^{55}$ descreveu a passagem do candidato a presidente da República Juscelino Kubitchek, quando os funcionários da Lumber foram reivindicar uma solução para a questão trabalhista.

O pessoal combinou em ir pedir socorro para ele. Que ele achasse uma solução. Então, os trabalhadores pareciam uma jagunçada, de tamanco, sapatos furados, bem maltrapilhos. Não tinham condição de comprar. Eu achei que o candidato não ia dar atenção, achando que eles eram jagunços. Mas, não ele desceu e deu atenção para todos. Cada um contava uma coisa, da miséria que estavam passando. Ele foi eleito e já mandou um representante do Rio de Janeiro para resolver a situação. Quem tinha idade, podia aposentar e os novos podiam ficar trabalhando para Ministério do Exército. Os que não queriam eram indenizados na forma da lei. ${ }^{56}$

Leoberto Leal, Deputado Federal catarinense, esteve em Canoinhas após a vitória de Juscelino Kubitschek, em missão especial ligada a solução pleiteada para o caso dos empregados, que já estava há quase um ano sem pagamento. Em junho de 1956, foi divulgado que o presidente da Republica Juscelino Kubitschek havia solicitado ao Congresso Nacional abertura de Crédito especial para pagamento de salários atrasados e indenizações aos

\footnotetext{
${ }^{53}$ BARRIGA VERDE. Presidente da Câmara Municipal de Canoinhas recebido pelo presidente Dr. Nereu Ramos e Ministro da Guerra General Lott. 26/01/1956. Ano XIX № 1014. BPESC.

${ }^{54}$ BARRIGA VERDE. Os empregados da “Lumber". 05/04/1956. Ano XIX № 1032. BPESC.

${ }^{55}$ Nascida em 12/06/1931, foi casada com o trabalhador da Lumber Francisco Gemra.

${ }^{56}$ GEMRA, Sybila. Entrevista concedida a Soeli Regina Lima, 2015.
} 
servidores da ex-Lumber. ${ }^{57}$ Observa-se, em matéria publicada no dia 05/08 /1956, a forma como se deu o término das agruras dos trabalhadores com vencimentos em atraso:

Finalmente foi resolvido o problema dos bravos servidores da ex-Lumber, hoje, “Campo de Instrução Marechal Hermes”, em Três Barras. Já foi enviada a importância de quase dezoito milhões de cruzeiros, para atender o pagamento dos salários, vencimentos e indenizações devidos àqueles servidores. O Ministério da Guerra vai indenizar e dispensar 136 empregados que espontaneamente resolveram retirar-se do trabalho. Entretanto 37 servidores optaram pela situação de extranumerários, preferindo assim, permanecer em suas funções, no Ministério da Guerra. [...] Ante os olhares esperançosos do povo de Canoinhas, Juscelino Kubitchek prometeu por fim ao drama da população tresbarrense. Prometeu, e em menos de cento e oitenta dias cumpriu sua palavra $!^{58}$

Após árdua batalha travada pelos trabalhadores e sua organização, a Sociedade União Operária, com o apoio do Sindicato dos Oficiais Marceneiros e Trabalhadores nas Indústrias de Serrarias e Móveis de Madeira de Canoinhas, em aliança com o advogado da Lumber, além de políticos da região, somadas a ação da imprensa chegam a uma solução para a causa trabalhista.

\subsection{Considerações finais.}

Muitos trabalhadores migraram para outras cidades, a economia local entrou em declínio. Dos 809 trabalhadores que atuavam na Southern Brazil Lumber and Colonization Company Inc. no ano de 1943, no final da questão trabalhista, apenas 37 servidores optaram por permanecer em suas funções no Ministério da Guerra, e 136 empregados “espontaneamente" resolveram retirar-se do trabalho. Esta fase de produção da serraria Lumber foi encerrada e inicia-se outro capítulo da história tresbarrense: a implantação de um campo militar na área da ex-serraria, agora ocupada pelo Exército Nacional. Permaneceu o patrimônio edificado localizado no centro da cidade e na memória daqueles que vivenciaram os últimos momentos daquela que foi a maior serraria da América do Sul.

Artigo recebido para publicação em 19/12/2016

Artigo aprovado para publicação em 28/05/2017

\footnotetext{
${ }^{57}$ BARRIGA VERDE. O General Henrique Teixeira Lott atende um apelo do ex- prefeito Generoso A. Prohmann sôbre o caso dos atrazados da ex-Lumber. 27/06/1956. Ano XIX № 1053. BPESC.

${ }^{58}$ BARRIGA VERDE. O Presidente Juscelino Kubtscheck cumpre o prometido aos servidores da ex-Lumber. O5/08/1956. Ano XIX № 1064. BPESC.
} 